\title{
A Prospective Study on Relation of Inferior Thyroid Artery with Recurrent Laryngeal Nerve at the Base of Thyroid Gland in Tamil Nadu Population
}

\author{
Nisha S.R. Manuel ${ }^{1}$, B. Anbumalar ${ }^{2}$, S. Manisha Raaj ${ }^{* 3}$.
}

${ }^{1}$ formerly Associate Professor, Government Medical College, Omandurar Estate, Wallajah road Chennai-2. Presently Associate Professor, Government Stanley Medical College, Chennai-1. The TN Dr. MGR Medical University, Chennai-32. Tamil Nadu, India.

${ }^{2}$ Associate Professor, Government Chengalpattu Medical College, Chengalpattu. The TN Dr. MGR Medical University, Chennai-32, Tamil Nadu, India.

${ }^{*}$ Assistant Professor, Government Coimbatore Medical College, Coimbatore. The TN Dr. MGR Medical University, Chennai-32, Tamil Nadu, India.

\section{ABSTRACT}

Background: The risk of injuring recurrent laryngeal nerves can result in voice or swallowing problems can be a major complication during thyroid surgeries. Intraoperative injury to RLN can be an issue and can have a detrimental impact on patients' quality of life. The incidence of injury to recurrent laryngeal nerve worldwide ranges from 0.5 to $20 \%$. To prevent such surgical complications of thyroid, a detailed anatomy of inferior vascular pedicle (inferior thyroid artery) and its relation to adjacent recurrent laryngeal nerve is required.

Aim: The aim of the study was, To find out the variable anatomical relationship between inferior thyroid artery and recurrent laryngeal nerve at the base of lateral lobes of thyroid gland.

Materials and methods: This descriptive study was conducted for a period of 72 months at the Department of Anatomy, Government Medical College, Omandurar Government Estate, Chennai-2, between January 2015 January 2021 by dissection method in 60 adult ( 54 male and 6 female) cadavers (60 - right \& 60 - left sides).

Results: Results were noted, tabulated and interpreted. It was found that the recurrent laryngeal nerve at the base of thyroid gland which was predominantly posterior on both sides (R-78.33\%, L- 100\%) to inferior thyroid artery and in $21.66 \%$ anterior to ITA on right.

Conclusion: The recurrent laryngeal nerve may lie anterior or posterior to inferior thyroid artery. In the present study, the recurrent laryngeal nerve was posterior most commonly on both sides to inferior thyroid artery. On the right, the second common presentation was the recurrent laryngeal nerve lying anterior to inferior thyroid artery.

KEY WORDS: Thyroid gland, Subclavian artery, Inferior thyroid artery, Recurrent laryngeal nerve.

Corresponding Author: Dr. S. Manisha Raaj, Assistant Professor, Government Coimbatore Medical College, Coimbatore. The TN Dr. MGR Medical University, Chennai-32, Tamil Nadu, India. E-Mail: manisharj2@gmail.com

Access this Article online

\section{Quick Response code}

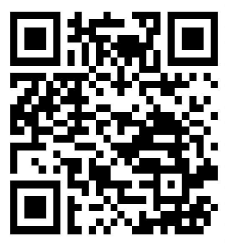

DOI: $10.16965 /$ ijar.2021.190
Journal Information

International Journal of Anatomy and Research ISSN (E) 2321-4287 | ISSN (P) 2321-8967

https://www.ijmhr.org/ijar.htm

DOI-Prefix: https://dx.doi.org/10.16965/ijar

Article Information

Received: 16 Nov 2021

Peer Review: 16 Nov 2021
Accepted: 04 Jan 2022

Published (O): 05 Mar 2022

Published (P): 05 Mar 2022

\section{INTRODUCTION}

Thyroid gland, with its two lateral lobes and isthmus extends from fifth or sixth tracheal ring to the oblique line of thyroid cartilage. Being invested by pre-tracheal fascia, which is thickened posteriorly, as the ligament of Berry, 
which is attached to the arch of the cricoid cartilage. Due to this posterior attachment the thyroid gland moves with larynx during deglutition [1].

The apex of each lateral lobe receives a superior thyroid artery and external laryngeal nerve. The base and deep structures of thyroid receive branches from inferior thyroid arteries and recurrent laryngeal nerve [1].

The inferior thyroid artery, is a branch of thyrocervical trunk of first part of subclavian artery. After looping with upward convexity at sixth cervical vertebral level it descends to reach the base of lateral lobe of thyroid. It enters the lower pole of the gland very close to recurrent laryngeal nerve [2].

The recurrent laryngeal nerve, a branch of Vagus (CNX) was described by Galen. It carries sensory, motor and parasympathetic fibres to laryngeal structures [2].

The recurrent laryngeal nerve on right, loops around the subclavian artery at the base of neck and on the left, loops around the arch of aorta below the ligamentum arteriosum. Then runs along the tracheoesophageal groove to enter into larynx posterior to cricothyroid articulation and deep to the inferior constrictor muscle [3].

At the inferior pole of thyroid, the right recurrent laryngeal nerve may cross anterior or posterior or in between, the branches of inferior thyroid artery. The left recurrent laryngeal nerve has a vertical ascent from superior mediastinum [3].

Hazem M. Zakaria et al [4] has quoted hoarseness was the usual sign of unilateral recurrent nerve injury. He also added that, temporary dysphonia or aphonia is usually transient lasting for a few days or months which can be attributed to oedema or traction injury or bruising or over handling of the recurrent laryngeal nerve during operative procedure [4]. If dysphonia persisted for more than six months, it can be due to a permanent damage to RLN which may have resulted as a result of cutting ligating or cauterization of the nerve [4]. Bilateral injury to RLN, is a medical emergency requiring tracheostomy due to airway obstruction [4].
OBJECTIVES: The aim of the study was to study the variable anatomical relationship between inferior thyroid artery and recurrent laryngeal nerve at the base of lateral lobes of thyroid gland.

\section{MATERIALS AND METHODS}

This descriptive study was conducted at department of Anatomy, Government Medical College, Omandurar Government Estate, Chennai-2 for a period of seventy two months between January 2015 to January 2021. After complete approval from Institutional Ethical Committee for the research protocol. About sixty adult cadavers ( 54 males and 6 females) aged between 50 - 75 years, were dissected. The adult cadavers were received from body donation after written informed consent. The cadavers were embalmed through femoral artery perfusion.

The methodology prescribed by Cunningham's Manual of dissection was carried out after incising the skin from chin to sternum in midline and reflected the skin flap infero-laterally. Platysma was reflected upwards keeping close to its deep surface. A transverse incision through the investing layer of deep cervical fascia was made from above the sternum and both sternocleidomastoid were reflected laterally. The deep cervical fascia was removed from below hyoid, which exposed the infrahyoid muscles between hyoid and sternum on both sides. The superior belly of omohyoid was displaced laterally. The infrahyoid muscles were separated in the midline to expose the pretracheal fascia. The fascia from the lateral lobes of thyroid gland were removed by blunt dissection which exposed the thyroid gland. Position of recurrent laryngeal nerve to inferior thyroid artery on both sides at the base of thyroid gland were observed [1].

\section{OBSERVATIONS}

In $21.66 \%(13 / 60)$ specimens the recurrent laryngeal on the right was anterior to the inferior thyroid artery. In 78.33\% (47/60) specimens the recurrent laryngeal on the right was posterior to the inferior thyroid artery. In $100 \%(60)$ specimens the recurrent laryngealon the left was posterior to the inferior thyroid artery. 


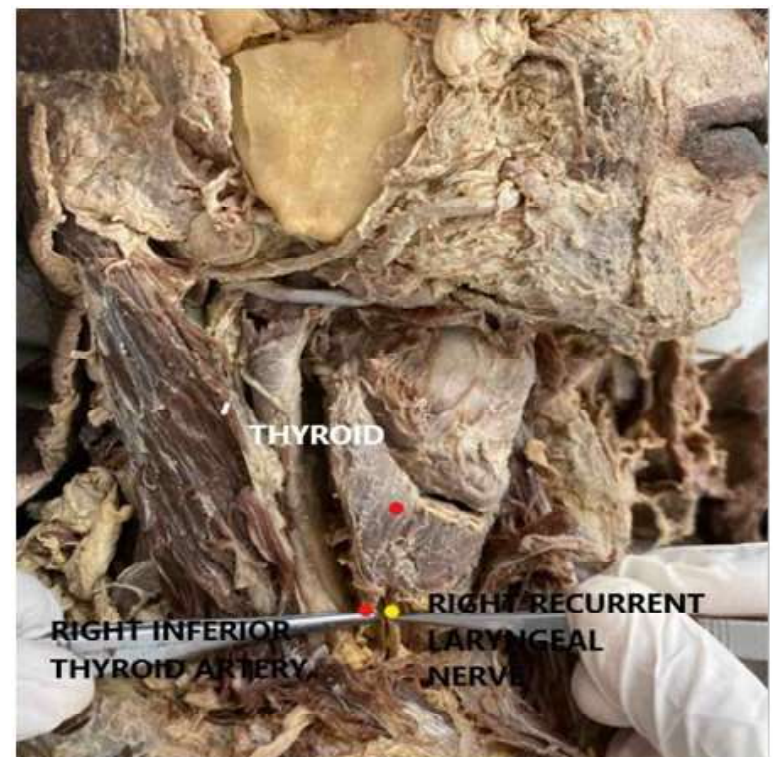

Fig. 1: Right Sided Recurrent Laryngeal Nerve Lying Posterior to Inferior Thyroid Artery.

COMPARISON OF RIGHT SIDED RLN WITH ITA

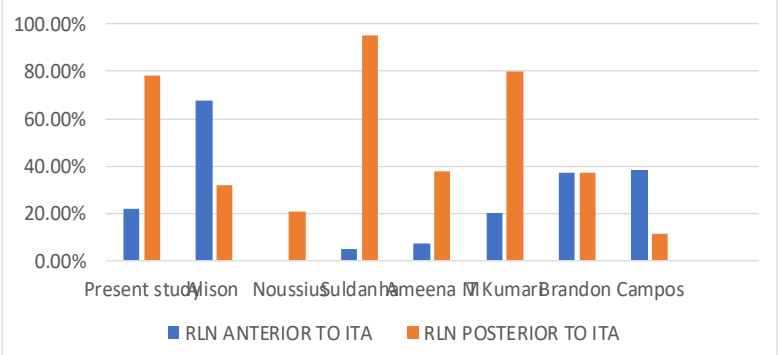

Fig. 3: Comparison Of Present Study With Previous Studies Right Sided Recurrent Laryngeal Nerve With Inferior Thyroid Artery.

Table 1: Relation of inferior thyroid artery to recurrent Anterior/ superficial to laryngeal nerve at the base of ITA thyroid gland.

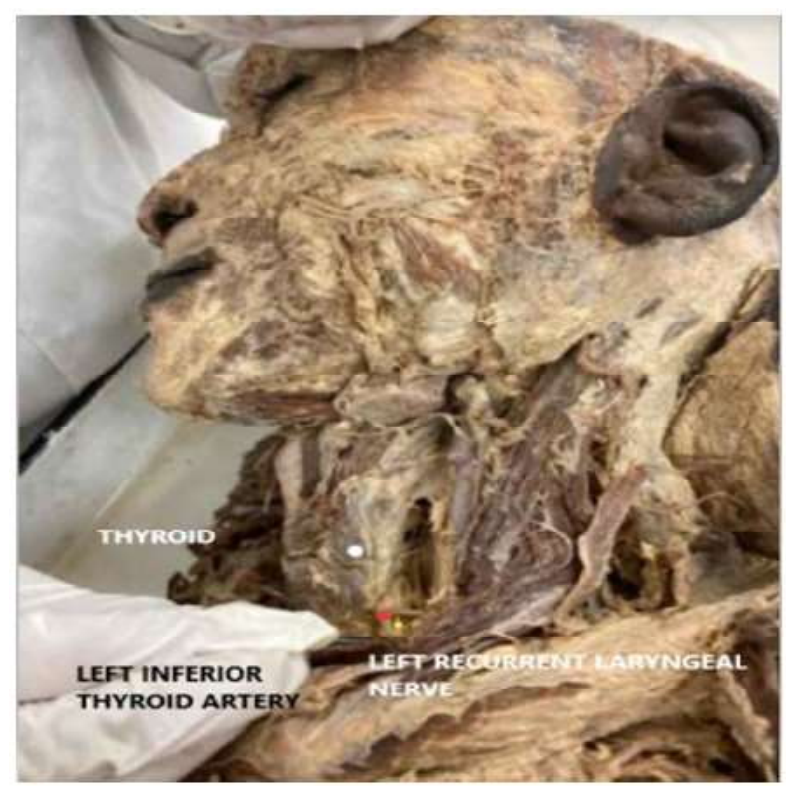

Fig. 2: Left Sided Recurrent Laryngeal Nerve Lying Posterior to Inferior Thyroid Artery.

COMPARISON OF LEFT SIDED RLN WITH ITA

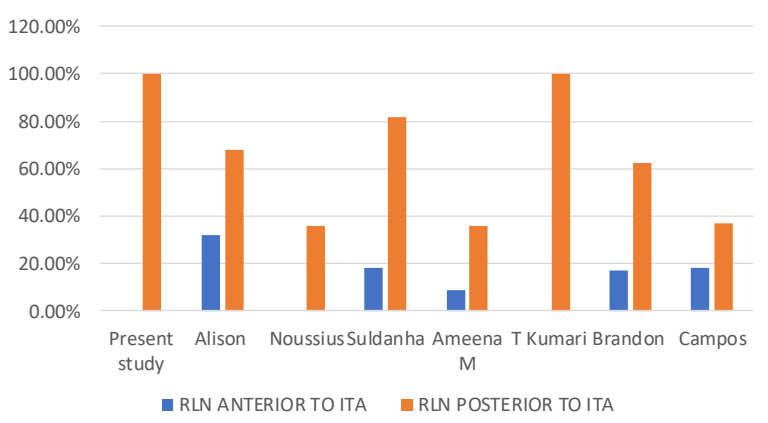

Fig. 4: Comparison Of Present Study With Previous Studies Left Sided Recurrent Laryngeal Nerve With Inferior Thyroid Artery.

\begin{tabular}{lcccc}
\hline \multirow{2}{*}{$\begin{array}{c}\text { Course of recurrent } \\
\text { Laryngeal Nerve }\end{array}$} & \multicolumn{2}{c}{$\begin{array}{c}\text { Right sided inferior } \\
\text { thyroid artery }\end{array}$} & \multicolumn{2}{c}{$\begin{array}{c}\text { Left sided inferior thyroid } \\
\text { artery }\end{array}$} \\
\cline { 2 - 5 } & Number & Percentage & Number & Percentage \\
\hline $\begin{array}{l}\text { Anterior/ superficial to } \\
\text { ITA }\end{array}$ & 13 & $21.66 \%$ & --- & --- \\
\hline Posterior / dorsal to ITA & 47 & $78.33 \%$ & 60 & $100 \%$ \\
\hline TOTAL & 60 & $99.99 \%$ & 60 & $100 \%$ \\
\hline
\end{tabular}

\section{DISCUSSION}

Dissected the neck of 60 cadavers. Relation of inferior thyroid artery to recurrent laryngeal nerve @ base of thyroid gland was studied. On both sides, the inferior thyroid artery originated from the thyrocervical trunk of the subclavian artery. Bilaterally the recurrent laryngeal nerve originated from the vagus. On right side, the nerve hooked the subclavian artery and ascended upward obliquely and reached the base of the right lateral lobe of thyroid gland either posterior (78.33\%) to inferior thyroid artery or anterior (21.66\%) to inferior thyroid artery. On left side, the nerve hooked the arch of aorta and ascended upward to base of the left lateral lobe of thyroid gland posterior(100\%) to inferior thyroid artery.

In the present study, the most common type of relation between ITA and RLN was, RLN being posterior to ITA on both sides of neck.

Hazem M. Zakaria et al [4] emphasized, that the incidence of injury to recurrent laryngeal 
Table 2: Comparison of present study with previous studies - relation of inferior thyroid artery to recurrent laryngeal nerve (right side).

\begin{tabular}{lcc}
\hline \multicolumn{1}{c}{ Authors } & $\begin{array}{c}\text { Right sided RLN } \\
\text { anterior to ITA }\end{array}$ & $\begin{array}{c}\text { Right sided RLN } \\
\text { posterior to ITA }\end{array}$ \\
\hline Present Study (2021) & $21.66 \%$ & $78.33 \%$ \\
\hline Alison M. Thomas et al (2020) [5] & $67.90 \%$ & $32.10 \%$ \\
\hline George Noussios et al (2020) [6] & -- & $20.78 \%$ \\
\hline Marina Saldanha et al (2019) [7] & $5 \%$ & $95 \%$ \\
\hline Ameena. M et al (2019) [8] & $7 \%$ & $38 \%$ \\
\hline T .Kumari et al (2017) [9] & $20 \%$ & $80 \%$ \\
\hline Brandon Micheal Henry et al (2016) [10] & $37.10 \%$ & $37 \%$ \\
\hline Campos B.A et al (2000) [11] & $38.04 \%$ & $11.26 \%$ \\
\hline
\end{tabular}

Table 3: Comparison of present study with previous studies - relation of inferior thyroid artery to recurrent laryngeal nerve (left side)

\begin{tabular}{lcc}
\multicolumn{1}{c}{ Authors } & $\begin{array}{c}\text { Left sided RLN } \\
\text { anterior to ITA }\end{array}$ & $\begin{array}{c}\text { Left sided RLN } \\
\text { posterior to ITA }\end{array}$ \\
\hline Present Study (2021) & --- & $100 \%$ \\
\hline Alison M. Thomas et al (2020) [5] & $32.10 \%$ & $67.90 \%$ \\
\hline George Noussios et al (2020) [6] & -- & $35.73 \%$ \\
\hline Marina Saldanha et al (2019) [7] & $18 \%$ & $82 \%$ \\
\hline Ameena.M et al (2019) [8] & $9 \%$ & $36 \%$ \\
\hline T .Kumari et al (2017) [9] & --- & $100 \%$ \\
\hline Brandon Micheal Henry et al (2016) [10] & $17.20 \%$ & $62.60 \%$ \\
\hline Campos B.A. et al (2000) [11] & $18.05 \%$ & $37.05 \%$ \\
\hline
\end{tabular}

nerve was high when thyroidectomy was performed for a malignant disease. In an aggressive thyroid cancer, the nerve may be sacrificed purposefully, if it had been encased by the neoplasm [4].

Injury to RLN, is most commonly unilateral and transient, but can also be bilateral and permanent. After surgery, about $12.5 \%$ of patients suffer from temporary vocal cord paralysis and $3.8 \%$ of patients experience permanent paralysis [4].

Skandalakis et al [12] concluded, that injury to RLN is more common when the nerve lies anterior or in between the ITA. Chiang FY ${ }^{[13]}$ et al highlighted, meticulous dissection to identify the RLN during operative procedures on thyroid, minimised the risk of RLNI. That it was very beneficial especially on the right side, as it had a predominance of anterior configuration [13].

With recent advances, intra-operatively, there is a preference to use nerve monitoring devices to reduce the incidence of RLN injury. But there are studies suggesting intraoperative nerve monitoring has not proven more effective than direct nerve visualization [4].

Permanent injuries of RLN are best avoided by identifying, carefully tracing and verifying the anatomic integrity of the path of RLN and also studying to its relation to ITA before clamping the vessel during thyroidectomy procedures at the base of thyroid gland [4].

The purpose of this study was to highlight the variable anatomical relationship of inferior thyroid artery to recurrent laryngeal nerve at the base of thyroid gland. The recurrent laryngeal nerve was predominantly posterior on both sides (R-78.33\%, L- 100\%) and in $21.66 \%$ anterior to ITA on right.

\section{CONCLUSION}

Surgical procedures of head and neck, such as radical neck dissection, cricothyroidotomy, conventional thyroidectomy or a minimally invasive options for thyroidectomy, reconstruction of an aneurysm, carotid endarterectomy treatments for cancers of head and neck, diagnostic and therapeutic catherization of neoplasms of neck may involve inferior thyroid artery $[4,14]$. In procedures like neck lift or closure of defects of anterior neck, superior thyroid artery (STAP) perforator is commonly preferred as the dominant perforator. Nowadays, inferior thyroid artery (ITAP) perforator flaps are also being tried as 
source vessel for cosmetic reconstructive procedures [15].

A detailed knowledge of the relation of inferior thyroid artery to recurrent laryngeal nerve will be of immense use to the surgeon during surgical procedures of head and neck regions. We recommend, the direct visual identification of RLN and to study its relation to ITA which has to be done prior to clamping of ITA as the gold standard to preserve the recurrent laryngeal nerve during operative procedures. Other techniques may be used as an adjunct to the gold standard [16]. The recurrent laryngeal nerve may lie anterior or posterior to the inferior thyroid artery. In the present study the recurrent laryngeal nerve was posterior most commonly on both sides to inferior thyroid artery. On the right, the second common presentation was the recurrent laryngeal nerve lying anterior to inferior thyroid artery.

\section{ABBREVIATION}

ITA- Inferior Thyroid Artery,

RLN- Recurrent Laryngeal nerve,

RLNI- Recurrent laryngeal nerve injury,

STAP-superior thyroid artery perforator,

ITAP- inferior thyroid artery perforator.

\section{Author contributions}

Nisha S. R. Manuel- The first draft preparation.

B. Anbumalar- Revising of the manuscript

S. Manisha Raaj- Final writeup of the manuscript

\section{Conflicts of Interests: None}

\section{REFERENCES}

[1]. G.J. Romanes, Cunningham's Manual of Practical Anatomy 15th Edition Vol III Head and neck and brain Pg:65 -67.

[2]. Neeta V Kulkarni, Clinical Anatomy (A Problem solving Approach) 3rd Edition Vol II Abd, Pelvis Perineum Head and Neck Brain and Cranial Nerves Pg:751

[3]. Keith L.Moore Arthur F. Dalley and Anne M.R.Agur - Moore Clinically Oriented Anatomy 7th Edition Pg:1043
[4]. Hazem M. Zakaria, Naif A Al Awad, Ali S. Al Kreedes, Abdul Mohsin A.Al- Mulhim, Recurrent laryngeal nerve injury in thyroid surgery Oman Med J,2011 Jan;26(1):34-38.

[5]. Alison M.Thomas, Daniel K.Fahim and Jickssa M.Gemechu, Anatomical variations of recurrent laryngeal nerve and implications for injury prevention during surgical procedures of the Neck: Diagnostics 2020;10:670.

[6]. George Noussios, Josif Chatzis, Sergios Konstantinindis, The Anatomical relationship of Inferior thyroid artery and recurrent laryngeal nerve: A review of literature and its clinical importance. Journal of Clinical medicine research 2020;12(10):640-646.

[7]. Marina Saldanha, Samantha K. Jayaramaiah, Rajeshwary Aroor, Vdisha S.Bhat, Relationship of Recurrent laryngeal nerve with Inferior thyroid artery. Otorhinology Clinics: An international Journal, 2019;11(2):27-29.

[8]. Ameena M, K. Jayasree, A study on relations of recurrent laryngeal nerve with trachea and inferior thyroid artery. Indian Journal of Applied Research 2019;9(1):1-3.

[9]. T.Kumari, Sajey P, Romi A study of relation of recurrent laryngeal nerve to inferior thyroid artery and thyroid gland. Journal of Evidence Based Medicine and Healthcare 2017;4(56):3406-3409.

[10]. Brandon Micheal Henry, Silvia Sanna, Beatrice Sanna,Wiley Periodicals, Inc. Head Neck 2017;39:177-186.

[11]. Campos BA, Henriques PR, Relationship between the recurrent laryngeal nerve and the inferior thyroid artery: a study in corpses. Rev Hosp Clin Fac Med Sao Paulo. 2000 Nov-Dec;55(6) 195-200.

[12]. Skandalakis JE, Droulias C, Harlaftis N, Tzinas S, Gray SW, Akin JT,Jr ., The recurrent laryngeal nerve., Am Surg, 1976;42(9):629-634.

[13]. Chiang FY,Wang LF, Huang YF, Lee KW, KuoWR., recurrent laryngeal nerve palsy after thyroidectmywith routine identification of the recurrent laryngeal nerve. Surgery.2005;137(3):342347.

[14]. Jeremy L Wilson, Warren M Rozen, Richard Ross, Michael W Findlay, Mark Ashton, Felix C Behan The superior thyroid artery perforator flap anatomical study and clinical series. Plastic and Reconstructive Surgery 2012;129(3):641-6.

[15].Mohammad Ali Azad, AKM Asaduzzaman, Mohammad Delwar Hossain, Relationship between Inferior thyroid Artery and recurrent Laryngeal nerve- A Study of 200 cases. Bangladesh J Otorhinolaryngol2016;22(2):60-65.

How to cite this article: Nish S. R.Manuel, B. Anbumalar, S. Manisha Raaj. A Prospective Study on Relation of Inferior Thyroid Artery with Recurrent Laryngeal Nerve at the Base of Thyroid Gland in Tamil Nadu Population. Int J Anat Res 2022;10(1):8221-8225. DOI: 10.16965/ijar.2021.190 